\title{
During The Venture of Prenatal Diagnosis of Thalassemia, a vis-à-vis Elucidated Collage of Genetic Polymorphism of West Bengal, India.
}

\author{
Rajlaxmi Basu', Arunangshu Biswas², Sila Chakrabarti' and Siddhartha Sankar Ray ${ }^{1 *}$
}

\begin{abstract}
Introduction: Molecular screening of Thalassemia is a burning issue especially for developing country where birth rate is high and most of the victims are from rural and from economically downtrodden part of the society. Methods: The present study reports about the molecular diagnosis and pattern identification of Thalassemia carrier parents and females, who are in certain condition to determine their genotype of Chorionic Villi sample (CVS) to combat birth of new thalassemia baby. Result: Data suggest for the year 2014 and 15 that IVS 1-5(G-C) genotype heterozygous is the most prevalent for each year and affected CVS are either IVS 1-5(G-C) homozygous or compound heterozygous cases containing IVS 1-5(G-C). Bihar, Hooghly, Kolkata, North 24 Parganas, South Dinajpur and North Dinajpur is showing significant difference. Few regions are with a little laxity of patient flow for prenatal diagnosis. Conclusion: This data is useful to make a genetic micro map of West Bengal and also gives the vivid distribution of different Thalassemia gene across the state.
\end{abstract}

Key words: Blood, Chorionic Villi Sample, Molecular Diagnosis, Thalassemia Carrier.
Rajlaxmi Basu', Arunangshu Biswas ${ }^{2}$, Sila Chakrabarti ${ }^{1}$ and Siddhartha SankarRay ${ }^{1 *}$ 'Institute of Hematology and Transfusion Medicine, Medical College, Kolkata-700073, INDIA. ${ }^{2}$ Department of statistics, Presidency University, Kolkata-700073, INDIA.

\section{Correspondence} Siddhartha Shankar Ray Institute of Hematology and Transfusion Medicine, Medical College, Kolkata-700073, INDIA.

Phone no: +919477303522

Email: siddharthasankarray@gmail.com

\section{History}

- Submission Date: 11-05-2016;

- Revised Date: 31-03-2017;

- Accepted Date: 17-07-2017.

DOI : 10.5530/ijmedph.2017.3.31

Article Available online

http://www.ijmedph.org/v7/i3

\section{Copyright}

(C) 2017 Phcog.Net. This is an openaccess article distributed under the terms of the Creative Commons Attribution 4.0 International license.

\section{INTRODUCTION}

Thalassemia, a hemoglobinopathy, is the most common monogenic disorder with an autosomal recessive inheritance. Around $6.8 \%$ of the global population are carriers of these defaulted genes with an annual birth of more than 300,000 children with a severe hemoglobin disorder, but for Eastern India prevalence is higher and the figure is approximately $10 \%{ }^{1}$ India's 1.2 billion population accounts for $17.3 \%$ of the global population and is one of the world's most diverse nation in respect of ethnic groups, regional languages and different religions. A large portion of people $(68.8 \%)$ live in rural areas. $8.14 \%$ of people belonging to different socio-economically downtrodden groups still live in isolation. Optimum management of a child with $\beta$ - thalassemia major involves an expenditure levy of Rs150,000/year to Rs 200,000/ year. ${ }^{2}$ As the child grows older, a multidisciplinary approach is needed which further spirals high the cost of management. A recent study from Kolkata in Eastern India where both $\beta$-thalassemia major and HbE- $\beta$-thalassemia are common, showed that when unrestricted funds were available through sponsored comprehensive care, there was a significant increase in the hemoglobin levels and a decrease in serum ferritin; and the clinical parameters as well as the quality of life of the patients were significantly better than those patients receiving routine care. ${ }^{3}$ Unfortunately, only $5-10 \%$ of patients in India can afford optimum care and the majority of patients are not even regularly transfused or chelated. ${ }^{4}$ Thus, there is a need to strengthen prevention programmers. Majority of the husbands do not accompany their wives to antenatal clinic and by the time couples at risk are identified, it is too late for a prenatal diagnosis. Thus, it is felt that due to the complexity of the Indian population, multiple target groups would have to be screened in different regions. It has been emphasized that a pre-requisite for a screening program would be the organization of adequate facilities to meet the demand both for screening and prenatal diagnosis. ${ }^{5}$ This is very important for a vast country like India. In 2010 the West Bengal government started a program named "State Thalassemia Control Programmed (STCP)" with the aim of creating awareness about Thalassemia and detection of Thalassemic patients as well as carriers. The government has taken every step to care for the existing Thalassemia patients by providing them with free blood transfusion in day care facilities, free chelation therapy, and regular monitoring of iron status by checking serum feritin level every three months. This involves a heavy drain on the available resources. A more cost-effective approach is to reduce the birth of new children with Thalassemia. Hence the STCP also decided to incorporate prenatal diagnosis for Thalassemia as one of the important tools to reduce the birth of new babies with Thalassemia. This report is a statistical representation that this medical programme has high social relevance. This report highlights the positive and promising outcome of the program and gives an insight of the approach being taken to maximize the deliverable i.e. checking the spread of Thalassemia in general 
through antenatal screening. This data also represents genetic distribution of Thalassemic carrier according to different districts and this data is substantially important for our future diagnosis and data interpretation.

\section{MATERIALS AND METHODS}

This work is being carried out as a part of State Thalassemia Control Program by Government of West Bengal. Sixteen Thalassemia control units have been established in different district hospitals to cover the maximum number of people to identify Thalassemia carriers by HPLC using Bio Rad Variant II, provide counseling and generate awareness. Samples are also collected from outreach camps in remote areas. Institute of Hematology and Transfusion Medicine (IHTM), Medical College is one of the two nodal centers with the facility to carry out pre-natal diagnosis and has been offering this facility since August 2010. We are also carrying out antenatal camps to check the Thalassemia carrier status of all women in certain condition attending the OPD of Gynecology \& Obstetrics Department. In our institute routine antenatal screening for thalassemia is carried out. Whenever the mother is identified as Thalassemia carrier the father's carrier status was checked and in case of both parents being carriers the underlying $\beta$-globin gene mutations were identified by routine molecular techniques like ARMS PCR. ${ }^{6}$

To identify these anomalies, the polymerase chain reaction-amplification refractory mutation system (PCR-ARMS) technique was used, the beta-Thalassemia mutation was detected by PCR-ARMS. Allele encountered in our study was IVS-I-5 (G-->C), Codon $6(\mathrm{~A}>\mathrm{T})$, codon 15 (G$->A)$, FS 41/42 (-CTTT), FS 8-9 (+ G), Codon 30 (G-->C), Codon 26 ( $\mathrm{G}>\mathrm{A}$ ). Fetal DNA analysis from chorionic villus tissue or amniotic fluid cells is generally done. Blood samples and analysis of blood by HPLC or molecular methods is also used when the couple at risk is identified late as often happens in India.

Here district wise analysis is done for the year 2014 and 15.

According to our data there are 19 existing districts or region where from patients pool were incurred which are written in the following tables.

Thalassemia is a genetic disorder, if we really want to eradicate it from our society where about $10 \%$ of the population is thalassemia carrier this routine screening is the quintessential way which is cost effective and can be performed within a viable time limit.

\section{RESULT}

Code level names (along columns in Table 1 below) are accordingly---

1. "A" ( IVS 1-5+Ve heterozygous)

2."A,C” (IVS 1-5 + Ve,Cd $15+\mathrm{Ve}$, affected )

3. "A,G" (IVS 1-5 + Ve, Cd $26+$ Ve, affected)

4. "A,E" (IVS 1-5 + Ve, FS 41-42+Ve, affected)

5. "A,P” (IVS 1-5 + Ve, FS 8,9+Ve, affected)

6. "A,I" (IVS 1-5+Ve, Cd 30+Ve, affected)

7. "B” (IVS 1-5 + Ve homozygous, affected)

8. "C" (Cd $15+$ Ve heterozygous, carrier $)$

9. "C,G” (Cd $15+\mathrm{Ve}, \mathrm{Cd} 26+\mathrm{Ve}$, affected $)$

10. “C,K” (Cd $15+\mathrm{Ve}, \mathrm{Cd} 6+\mathrm{Ve}$, affected $)$

11. "D” (Cd $15+$ Ve, homozygous, affected)

12. "E” (FS 41-42 + Ve heterozygous)

13. "E,G" (FS 41-42+Ve, Cd $26+\mathrm{Ve}$, affected)

14. "E,I" (FS 41-42+Ve,Cd $30+\mathrm{Ve}$, affected)

15. " $\mathrm{G}$ ” (Cd $26+$ Ve heterozygous)

16. "G,I" (Cd $26+\mathrm{Ve}, \mathrm{Cd} 30+\mathrm{Ve}$, affected)

17. "H” (Cd $26+$ Ve homozygous affected)
18. "I" (Cd $30+$ Ve Heterozygous)

19. "J" (Cd $26+$ Ve homozygous affected)

20. "K" (Cd 6+Ve heterozygous)

21. "NORMAL" = when each allele are in normal condition

District wise proportion of the genotype IVS 1-5(G-C) heterozygous

$\begin{array}{llllll}0.6176471, & 0.0000000, & 0.4000000 & 0.5192308 & 0.5135135 & 0.4210526\end{array}$

$\begin{array}{lllllll}0.3611111 & 0.5000000 & 0.1785714 & 0.1333333 & 0.3478261 & 0.5000000\end{array}$

$\begin{array}{lllllll}0.4035088 & 0.0000000 & 0.8000000 & 0.0000000 & 0.5806452 & 0.4659091\end{array}$

0.5238095

Code level names (along columns in Table 2 below) for the year 2105 are accordingly---

1. "A" ( IVS 1-5+Ve heterozygous)

2. "A,E” (IVS 1-5 + Ve, FS 41-42+Ve, affected)

3. "A,G" (IVS 1-5 +Ve, Cd $26+$ Ve, affected)

5. "A,C” (IVS 1-5 + Ve, Cd $15+\mathrm{Ve}$, affected)

4. "A,I" (IVS 1-5 + Ve, Cd 30+Ve, affected)

6. "B” (IVS 1-5 + Ve homozygous, affected)

7. "C" (Cd $15+$ Ve heterozygous, carrier)

8. "E" (FS 41-42 + Ve heterozygous)

9. "E,G” (FS 41-42+Ve, Cd 26 + Ve, affected)

10. "E,K” (FS 41-42+Ve, Cd 6+Ve, affected)

11. "G" (Cd 26+Ve heterozygous)

12. "I" (Cd $30+$ Ve Heterozygous)

13. "K" (Cd 6+Ve heterozygous)

14."M" (HbD heterozygous)

15 "N" (Cd12+Ve, heterozygous)

16. "NORMAL" = when each allele are in normal condition

17. "P” (FS 8-9 + Ve heterozygous)

18. "R" ( 6,9 bp deletion)

District wise proportion of the genotype IVS 1-5(G-C) heterozygous

Prop of gene coded A: 0.5000000, 0.8333333, $0.3529412,0.4927536$, $0.4888889,0.71428570 .4523810,0.43333330 .0000000,0.3214286$, $0.5000000,0.5647059,0.0000000,0.60869570 .5578947,0.5000000$, $0.5000000,0.5333333$

We see that the gene coded "A" is dominant across all the districts in both the years. The cases where the proportion is close to 0 , we see that the corresponding sample size of the district is only of a single figure. Hence we can discard those cases.

We then test if the spread of the gene coded "A" is uniform over all the districts /states/region in the year 2014 and 2015. Note that we perform the analysis only over the districts /states/ region for which data is available for both the years. Let $\mathrm{k}$ be the number of districts /states/ region over which the test is carried out. In this case $\mathrm{k}=17$.

That is, we want to formally test if $\mathrm{p}_{1, \mathrm{i}}\left(\mathrm{p}_{0, \mathrm{i}}\right), \mathrm{i}=1,2, \ldots, \mathrm{p}$ be the proportion of gene $\mathrm{A}$ for the $\mathrm{i}^{\text {th }}$ district for 2014 (2015) then :

$\mathrm{H}_{0}: \mathrm{p}_{1, \mathrm{i}}=\mathrm{p}_{0, \mathrm{i}}$, for all $\mathrm{i}=1,2, \ldots, \mathrm{k}$ against the alternative

$\mathrm{H}_{1}: \mathrm{p}_{1, \mathrm{i}}$ not equal to $\mathrm{p}_{0, \mathrm{i}}$, for at least one $\mathrm{i}$.

Since the sample size is moderately large we apply a large sample test. $\chi^{2}=4 \sum_{i=1}^{k}\left(\sqrt{n_{i, 1}} \sin ^{-1} \sqrt{\bar{p}_{i, 1}}-\sqrt{n_{i, 0}} \sin ^{-1} \sqrt{\bar{p}_{i, 0}}\right)^{2}$, under the null hypothesis of equal proportion the test statistics follows the chi-square distribution with $\mathrm{k}$ degrees of freedom,

where

$\bar{p}_{i, 1}=$ estimated proportion of the gene coded "A" in $\mathrm{i}^{\text {th }}$ class of 2014;

$\bar{p}_{i, 0}=$ estimated proportion of the gene coded "A" in i $\mathrm{i}^{\text {th }}$ class of 2015; 
Table 1: District wise-Gene distribution for the year 2014.

\begin{tabular}{|c|c|c|c|c|c|c|c|c|c|c|c|c|c|c|c|c|c|c|c|c|c|c|}
\hline & 1 & 2 & 3 & 4 & 5 & 6 & 7 & 8 & 9 & 10 & 11 & 12 & 13 & 14 & 15 & 16 & 17 & 18 & 19 & 20 & 21 & Total \\
\hline Bankura & 21 & 3 & 0 & 0 & 0 & 2 & 1 & 3 & 0 & 0 & 0 & 1 & 0 & 0 & 1 & 0 & 0 & 0 & 0 & 0 & 2 & 34 \\
\hline Bihar & 0 & 0 & 0 & 0 & 0 & 0 & 0 & 1 & 1 & 0 & 0 & 0 & 0 & 0 & 1 & 0 & 0 & 0 & 0 & 0 & 2 & 5 \\
\hline Birbhum & 12 & 0 & 0 & 0 & 3 & 0 & 2 & 2 & 0 & 0 & 0 & 0 & 0 & 0 & 7 & 1 & 0 & 1 & 0 & 0 & 2 & 30 \\
\hline Burdwan & 27 & 0 & 0 & 0 & 3 & 1 & 3 & 1 & 0 & 0 & 0 & 1 & 1 & 0 & 5 & 0 & 0 & 2 & 0 & 0 & 8 & 52 \\
\hline E.Midnapore & 38 & 0 & 1 & 0 & 6 & 1 & 5 & 1 & 2 & 0 & 0 & 2 & 1 & 0 & 8 & 0 & 0 & 2 & 0 & 0 & 7 & 74 \\
\hline Hoogly & 16 & 0 & 0 & 0 & 0 & 0 & 7 & 4 & 0 & 0 & 0 & 0 & 0 & 0 & 8 & 0 & 0 & 0 & 0 & 0 & 3 & 38 \\
\hline Howrah & 13 & 0 & 0 & 0 & 5 & 1 & 1 & 2 & 1 & 0 & 0 & 0 & 0 & 0 & 8 & 0 & 1 & 3 & 0 & 0 & 1 & 36 \\
\hline Jharkhand & 4 & 0 & 0 & 0 & 0 & 0 & 3 & 0 & 0 & 0 & 0 & 0 & 0 & 0 & 0 & 0 & 0 & 0 & 0 & 0 & 1 & 8 \\
\hline Kolkata & 5 & 0 & 0 & 0 & 2 & 0 & 0 & 4 & 0 & 0 & 1 & 0 & 0 & 0 & 10 & 0 & 0 & 2 & 0 & 0 & 4 & 28 \\
\hline Malda & 2 & 0 & 0 & 0 & 2 & 0 & 0 & 0 & 0 & 0 & 0 & 0 & 0 & 0 & 7 & 0 & 0 & 0 & 0 & 2 & 2 & 15 \\
\hline Murshidabad & 8 & 0 & 0 & 1 & 3 & 0 & 1 & 0 & 0 & 0 & 0 & 2 & 1 & 0 & 6 & 0 & 0 & 0 & 0 & 0 & 1 & 23 \\
\hline Nadia & 16 & 0 & 0 & 0 & 4 & 0 & 2 & 1 & 0 & 0 & 0 & 0 & 0 & 0 & 5 & 0 & 0 & 0 & 0 & 0 & 4 & 32 \\
\hline N.24 pargana & 23 & 0 & 0 & 0 & 9 & 0 & 7 & 3 & 1 & 0 & 0 & 0 & 0 & 0 & 11 & 0 & 0 & 0 & 0 & 0 & 3 & 57 \\
\hline N.Dinajpur & 0 & 0 & 0 & 0 & 0 & 0 & 0 & 0 & 0 & 0 & 0 & 0 & 00 & 0 & 2 & 0 & 0 & 0 & 0 & 0 & 0 & 2 \\
\hline $\begin{array}{l}\text { From other } \\
\text { itals(Anonymous) }\end{array}$ & 8 & 0 & 0 & 0 & 0 & 0 & 0 & 0 & 0 & 0 & 0 & 2 & 0 & 0 & 0 & 0 & 0 & 0 & 0 & 00 & 0 & 10 \\
\hline Odissa & 0 & 0 & 0 & 0 & 0 & 0 & 0 & 1 & 0 & 1 & 0 & 0 & 0 & 0 & 0 & 0 & 0 & 0 & 0 & 1 & 0 & 3 \\
\hline Purulia & 18 & 0 & 0 & 0 & 0 & 0 & 4 & 0 & 0 & 0 & 0 & 0 & 0 & 0 & 3 & 0 & 0 & 3 & 1 & 0 & 2 & 31 \\
\hline S.24 pargana & 82 & 0 & 0 & 2 & 11 & 3 & 13 & 3 & 1 & 0 & 0 & 3 & 0 & 2 & 37 & 0 & 1 & 6 & 0 & 0 & 12 & 176 \\
\hline W.Midnapore & 22 & 1 & 0 & 0 & 0 & 0 & 6 & 1 & 0 & 0 & 0 & 0 & 0 & 0 & 6 & 0 & 0 & 0 & 0 & 0 & 6 & 42 \\
\hline Total & 315 & 4 & 1 & 3 & 48 & 8 & 55 & 27 & 6 & 1 & 1 & 11 & 3 & 2 & 125 & 1 & 2 & 19 & 1 & 3 & 60 & 696 \\
\hline
\end{tabular}

Table 2: District wise-Gene distribution for the year 2015.

\begin{tabular}{|c|c|c|c|c|c|c|c|c|c|c|c|c|c|c|c|c|c|c|c|}
\hline & 1 & 2 & 3 & 4 & 5 & 6 & 7 & 8 & 9 & 10 & 11 & 12 & 13 & 14 & 15 & 16 & 17 & 18 & Total \\
\hline Bankura & 15 & 0 & 1 & 0 & 0 & 0 & 1 & 1 & 0 & 0 & 5 & 2 & 0 & 0 & 1 & 3 & 1 & 0 & 30 \\
\hline Bihar & 10 & 0 & 0 & 0 & 0 & 0 & 0 & 0 & 0 & 0 & 1 & 0 & 0 & 0 & 0 & 1 & 0 & 0 & 12 \\
\hline Birbhum & 12 & 0 & 2 & 0 & 0 & 0 & 2 & 0 & 0 & 0 & 8 & 4 & 0 & 0 & 0 & 3 & 3 & 0 & 34 \\
\hline Burdwan & 34 & 1 & 3 & 1 & 0 & 5 & 1 & 4 & 1 & 0 & 9 & 3 & 0 & 0 & 0 & 7 & 0 & 0 & 69 \\
\hline E.Midnapore & 22 & 0 & 1 & 0 & 0 & 2 & 0 & 1 & 0 & 2 & 9 & 0 & 1 & 0 & 0 & 7 & 0 & 0 & 45 \\
\hline Hoogly & 30 & 1 & 0 & 0 & 0 & 3 & 0 & 1 & 0 & 0 & 3 & 0 & 0 & 0 & 0 & 4 & 0 & 0 & 42 \\
\hline Howrah & 19 & 1 & 3 & 0 & 1 & 2 & 1 & 2 & 0 & 0 & 8 & 0 & 0 & 0 & 0 & 5 & 0 & 0 & 42 \\
\hline Jharkhand & 0 & 0 & 0 & 0 & 0 & 0 & 0 & 0 & 0 & 0 & 0 & 0 & 0 & 0 & 0 & 0 & 0 & 0 & 0 \\
\hline Kolkata & 13 & 0 & 0 & 0 & 0 & 2 & 0 & 1 & 0 & 0 & 8 & 1 & 0 & 1 & 2 & 2 & 0 & 0 & 30 \\
\hline Malda & 0 & 0 & 00 & 0 & 0 & 0 & 0 & 0 & 0 & 0 & 2 & 0 & 0 & 0 & 0 & 1 & 0 & 0 & 3 \\
\hline Murshidabad & 9 & 0 & 3 & 0 & 0 & 0 & 5 & 2 & 0 & 0 & 7 & 0 & 0 & 0 & 0 & 2 & 0 & 0 & 28 \\
\hline Nodia & 11 & 0 & 0 & 0 & 0 & 1 & 0 & 2 & 0 & 0 & 4 & 0 & 0 & 0 & 0 & 4 & 0 & 0 & 22 \\
\hline N.Dinajpur & 1 & 0 & 0 & 0 & 0 & 0 & 0 & 1 & 0 & 0 & 0 & 0 & 0 & 0 & 0 & 0 & 0 & 0 & 2 \\
\hline N.24 pargana & 48 & 0 & 3 & 0 & 0 & 6 & 2 & 2 & 0 & 0 & 15 & 2 & 0 & 0 & 0 & 5 & 1 & 1 & 85 \\
\hline $\begin{array}{c}\text { From other } \\
\text { Hospitals }\end{array}$ & 0 & 0 & 0 & 0 & 0 & 0 & 0 & 0 & 0 & 0 & 0 & 0 & 0 & 0 & 0 & 0 & 0 & 0 & 0 \\
\hline Orissa & 0 & 0 & 0 & 0 & 0 & 1 & 0 & 0 & 0 & 0 & 0 & 1 & 1 & 0 & 0 & 0 & 0 & 0 & 3 \\
\hline Purulia & 14 & 0 & 0 & 0 & 0 & 3 & 0 & 1 & 0 & 0 & 0 & 0 & 3 & 0 & 0 & 2 & 0 & 0 & 23 \\
\hline S.24 pargana & 53 & 0 & 5 & 0 & 0 & 5 & 0 & 0 & 0 & 0 & 19 & 3 & 0 & 1 & 0 & 7 & 2 & 0 & 95 \\
\hline S.Dinajpur & 3 & 0 & & - & - & - & - & - & - & - & 2 & & - & - & - & 1 & 0 & 0 & 6 \\
\hline W. Midnapore & 16 & 0 & 0 & 0 & 0 & 0 & 2 & 0 & 0 & 0 & 4 & 0 & 0 & 0 & 0 & 8 & 0 & 0 & 30 \\
\hline Tolal & 310 & 3 & 21 & 1 & 1 & 29 & 15 & 18 & 1 & 2 & 104 & 5 & 3 & 3 & 61 & 1 & 7 & 1 & 601 \\
\hline
\end{tabular}


$n_{i, 1}=$ sample size of $\mathrm{i}^{\text {th }}$ class of 2014

$n_{i, 0}=$ sample size of $\mathrm{i}^{\text {th }}$ class of 2015;

and $1 \leq i \leq k$ where $\mathrm{k}$ is the number of classes. We reject the null hypothesis if the observed value of the test statistics $\chi_{o b s .}^{2}>\chi_{k, \alpha}^{2}$. where $\chi_{k, \alpha}^{2}$. is the $(1-\alpha)$ quintile of a chi-square distribution with $\mathrm{k}$ degrees of freedom. In our case, $\chi_{o b s .}^{2}=368.3$ and $\chi_{k, \alpha .}^{2}=27.58$. Alternately the p-value of this test is very close to 0 and therefore the null hypothesis is trivially rejected. Here chi-square test is performed for the equality of population proportion in a sample of unequal sizes from $\mathrm{k}(=17)$ populations. As the number of pairs is too large, was not performed a pairwise test of equality of population proportion. This is the reason the omnibus chi-square test is performed, which is quite standard in such cases. The formula looks complicated since the sin inverse transform is applied in this case. This is a technical condition which will ensure that the variance of the sample proportion is not a function of any unknown parameters.

This means that the distribution of the gene coded " $\mathrm{A}$ " over the districts /states/region are significantly different over the two years. On further pairwise analysis, it revealed that the districts/States/region Bihar, Hooghly, Kolkata, North 24 Parganas, South Dinajpur and North Dinajpur show significant difference.

In these tables the numerical data of patient flow for each districts/ state/ region is depicted. Now the lens is arrested to find out which districts/ region/ states get less patient flow compare to 2014. From data is it cleared that Bankura, Purulia, West Midnapore, East Midnapore, Malda, Nodia, south 24 Pargana and Jharkhand were showing slight laxity of patient flow in the consecutive year 2015 .

\section{DISCUSSION}

Here, it is observed from the above data set and result that IVS1-5(G-C) heterozygous are the most dominant genotypes in Eastern India based state named West Bengal. For the year 2015 region number 13 is showing absolute prevalence of IVS 1-5(G-C) heterogynous pattern but it is due to narrow margin of patient flow from this particular region, besides each region $2,6,14$ are showing $50 \%$ or $>50 \%$ proportion of IVS1-5(GC) heterozygous genotype including both parents and, new born baby and CVS. Likewise in the year 2014 also showing the same trail, here, region $1,4,5,8,12$, and 15 were showing highest proportion substantially and region 15 has almost $80 \%$ population were with this concern genotype. In the year 2014 and 15 compound heterozygous cases containing 1-5(G-C) were all from CVS not from antenatal screening. By prenatal diagnosis genotypes had been determined and parents were admonished to terminate pregnancy to alleviate the birth of Thalassemia affected baby using this present tool. Finally bit special attention should be given to those districts/ states/ region where patient flow is slightly less compare to 2015. Our result proves that our nodal institution is able to give the clarion call to neighboring states too, and Jharkhand, Bihar and Orissa ( all are geopolitically different states) are the burning examples which established that this agenda is going to be pervasive.

\section{Limitation of the Study}

Though the State Thalassemia Control Programme is going in the right direction but still quite a few obstacles have to be overcomed since there are many social obduracy and village women are still obsessed with prejudices and social stigma. Regionally there are sporadic religious obstacle which is yet to be subverted. Despite having a healthy daughter many families opt for a male child and avid for it resulting some times in toll to the health security, a new thalassemia male child is added. They refuse PND in the hope of begetting a male child.

\section{CONCLUSION}

This brief and present report is showing the Thalassemia genotype pattern of the concern state West Bengal and data volume also convey the report about patient pool of a densely populated state where more concern should be generated as well as birth control of thalassemic baby this a resolution for the marginal population.

The population density of State of West Bengal is highest, and it was previously said that about $10 \%$ of the population is carrier, so special attention should be given to this state. with about 5000 fresh cases of thalassemia being reported in this state every year, West Bengal ${ }^{7}$ is the state with highest number of patients. Now the question is whether prevention in national level is cost effective or not. It is believed that it is cost effective. In a study done in Iran, it was concluded that the ratio of cost of treatment to prevention of thalassemia is $16: 1.6{ }^{8}$ A world Health Organization committee, in this study stated that in Cyprus, the annual cost of running the screening and and prenatal diagnosis program was found to be about equal to the cost of treatment of all existing patients of five years, In Sardinia the committee estimated that a $90 \%$ reduction in the incidence of thalassemia disease would recoup the cost of setting up a prevention program in three years from the start of the services; therefore the total cost of treatment would fall steadily over the next five years to about one-fifth of the projected cost of treatment. ${ }^{9}$ Prevention of thalassemia, therefore is practical, feasible and theb answer to the agony of so many children, families and nations. A concerted effort is in pipeline to run National Thalassemia Program.

\section{ACKNOWLWDGEMENT}

Authors are grateful to the funding body "State Thalassemia Control Project" Sponsored by Govt. of West Bengal. Our thanks to all the workers of STCP for their consistent and diligent efforts. Our special thanks to STCP technician Mrs Roma Roy Saymal to wield the lab hand.

\section{CONFLICT OF INTEREST}

There is no conflict of interest at all.

\section{ABBREVIATION USED}

ARMS: Amplification refractory mutation system; PCR: polymeric chain reaction; Cd: Codon; EDTA: Ethylenediaminetetraacetic acid; IVS: Intervening sequence; FS: Frame Shift mutation.

\section{REFERENCES}

1. Weatherall DJ, Akinyanju, $\mathrm{O}$, Fucharoen $\mathrm{S}$, et al. Inherited disorders of haemoglobin. In: Jamison D, et al, eds. Disease control priorities in developing countries. 2nd ed. New York: Oxford University Press and the World bank; 2006;663-80.

2. Verma IC, Saxena R, Kohli S. Past, present \& future scenario of thalassaemic care \& control in India. The Indian journal of medical research. 2011;134(4):507.

3. Thacker N. Prevention of thalassemia in India. Indian Pediatr 2007;44:647-8

4. Colah R, Gorakshakar A, Nadkarni A, Phanasgaonkar S, Surve R, Sawant P, et al. Regional heterogeneity of $\beta$-thalassemia mutations in the multi ethnic Indian population. Blood Cells, Molecules, and Diseases. 2009;42(3):241-6.

5. Chakrabarti P, Bohara VK, Ray S, Ray SS, Nath UK, Chaudhuri U. Can the availability of unrestricted financial support improve the quality of care of thalassemics in a center with limited resources? A single center study from India. Thalassemia Reports. 2012;3(1):2.

6. Cao A, Kan YW. The prevention of tha- Prenatal diagnosis Non-commercial use only Thalassemia Reports 2014; 4:1955; 89 Thalassemia. Cold Spring HarbPerspect Med 2013;3:011775

7. Times Of India,: jan1, 2013

8. Ghotbi N, t Tsukatni T. An economic rview of the national screening policy to prevent thalassemia major in Iran. From: www.kier.kyoto-u.ac.jp/DP / DP 562 Accedssed $6^{\text {th }}$ August 2007

9. World health organizatio0n: Human genetics program. Division of communicable Diseases. Community Control of hereditary anaemias: memorandum for WHO meeting. Bull. WHO 1983;61:63-80 